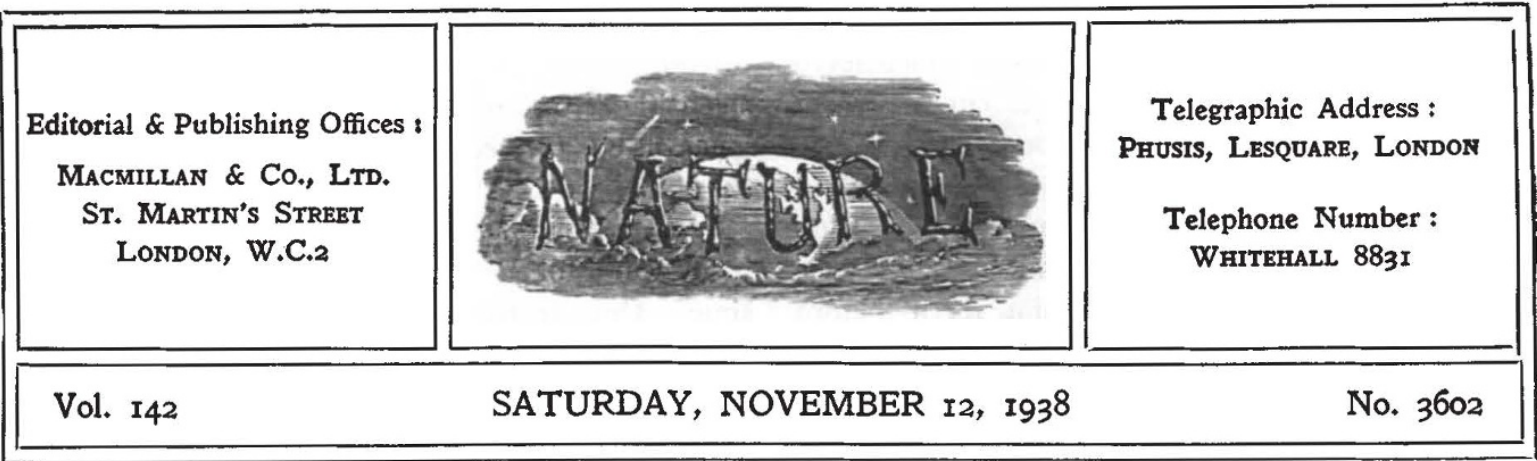

\title{
Human Evolution and Mechanization
}

$\mathrm{N}$ an address* at the end of last year before 1 the American Society of Mechanical Engineers, Prof. Earnest A. Hooton, of the Peabody Museum, Harvard University, surveyed the course of evolution in the primate stem, regarding it as a series of adaptations in a progression towards the specifically human attributes of tool-making and tool-using. He showed how each of the modifications in structure, such as the development of the hand, with its opposable thumb and sensitive finger-tips, of the foot as a movable point of balance, of upright stature, with the consequent visceral readjustments, of stereoscopic vision and of the central nervous system and the changes in form, size and complexity of the brain, were all antecedent conditions in the attainment and elaboration of a material culture. The results of recent observation and experiment with monkeys and apes have also shown how structure and mentality in each branch of the pithecoids has militated against the attainment of anything more than some rudimentary form of mechanical achievement, while the failure to develop an articulate language has precluded the passing on of experience and acquired knowledge, which is an essential element in human cultural progress.

We will not attempt to follow Prof. Hooton in detail as he traced the influence of the invention of tools from the time when it relieved man of the necessity of further structural adaptation in the struggle for survival-tools, as he says, made organic adaptation obsolete- to the dominance of the machine in modern civilization. There are, however, two points which call for special

" "The Simian Basis of Human Mechanics or Ape to Engineer". The Tenth Henry Robinson Towne Lecture delivered at the Annual Meeting, New York, N.X., Dec. 6-10, 1937, of the American Society of Mechanical Engineers. Reprinted from Mechanical Engineering of January 1938, Antiguty of June 1938. consideration. Of these, the first is a development of the familiar principle that disuse of an organ leads to its atrophy. Prof. Hooton suggests that when human evolution emphasized cerebral development, it diverted nutriment from other parts of the body, and the less active organs diminished in size. While, however, he goes on, no man has need of the strength of the ape, he ought to need the brains of a man; he should not be able to survive with the brains of a moron. The machine and mass-production of modern civilization favour the survival of the physically unsound and the mentally impotent by relieving mankind of the opportunity, or indeed the necessity, for physical and mental exercise. The second point maintained by Prof. Hooton is that invention is the product of the individual and is accepted with reluctance by the many, if indeed it be not actually suppressed, though the conservatism of the masses is responsible for the preservation and stability of the culture already achieved.

Prof. Hooton intentionally paints in darkest colours the picture of present-day trends in mechanized society, which he regards as rushing headlong along the downward path on a well engineered road. Man's mechanized science, he says, has so far outstripped his biological status and social ideals and behaviour that it has become a menace. What we must do, he concludes, is to direct a modicum of that high intelligence and creative ability, which is too much monopolized by mechanical science, to the study of ways and means of repairing and improving the human machine.

With this conclusion all will be in hearty sympathy, especially in so far as it implies the building of a better race and the study of the 
capabilities stored up in our species through the millions of years of primate evolution which have culminated in man. At the same time, certain comments present themselves for consideration. It is possible to exaggerate the deadening effect of mechanization on the human mind. Much depends upon the individual and his character, qualities and interests. In the days before mechanization, it was the deadening effect of manual labour of any kind, now contrasted with mechanization, which was blamed, and often not unjustly, for the inertia and the baseness of the masses in our population. They always have been and always will be coarse in some degree, while they are unleavened by the desire and the opportunity for self-development. Such an opportunity must now come in our modern civilization through the development of a regulated mechanization, which will give labour the necessary leisure.

But again, surely the moron-like character of the 'base mechanic' is much exaggerated. The mental and social effects of mechanization through atrophy of the powers of the mind, and the dangers of passive receptivity induced by gramophone, wireless and the cinema are patent, indeed, but are they really so serious as they are said to be ? The introduction of the talking film has placed the cinema more nearly on the level of the theatre as an educative and cultural influence. Its failure is now in its material rather than in its method of presentation-this does not refer to natural history and other instructional films-and the shortcomings of the film as drama are being remedied rapidly. Both cinema and wireless now reach thousands, where formerly the theatre, music and literature influenced hundreds, or it may be only tens. The effect is to be seen around us everywhere in daily life in a raising of the general cultural level. Nor is individual performance likely to be seriously affected. Photography and the gramophone were, it was feared, to put an end in turn to painting and music. Both have helped the development of these arts, and the understanding of their principles, while as regards the individual executant, they may possibly have eliminated a few who never would have attained perhaps even a mediocre competence.

In a sense, new inventions are the work of an individual, yet in all but backward cultures the individual, unless in exceptional instances, is the spear-head, while the general cultural level of society is the shaft of the spear. The individual gathers up the threads of a general cultural trend.
This applies even in highly specialized branches of thought, as, for example, when a whole body of scientific workers is proceeding along certain general, but related, lines of development. Darwin was indebted to a general drift of philosophic and scientific thought and speculation, which had been incubating for a generation or more before his time. Only in the more primitive type of society existing in complete isolation could such conditions as Prof. Hooton pictures prevail-a society in which innovation by an individual would be suppressed, or adopted only with extreme reluctance by the conservative masses. Cultural advance is usually a process of cross-fertilization, that overcomes by one means or another the natural conservatism which is undoubtedly a prominent feature in the make-up of a primitive group. The effects of such cross-fertilization of cultures can be seen in the processes of growth of all the great civilizations of the Old World. Of its advantages and disadvantages we are ourselves, perhaps, the most conspicuous example.

What may be termed the humanization of future progress in a mechanistic world-a world in which, as Western civilization spreads more and more widely to the peoples of less advanced culture, mechanization will increase rather than diminishis more likely to be brought about by a crossfertilization of the existing cultures of the different peoples of the world than by internal development of a nationalized ideal. For while the nationalized ideal ex hypothesi is separatist in tendency, it is only by a general pooling of ideals and ideas, such as for example in the biological study of man which Prof. Hooton rightly desiderates, that we can hope to solve the problems threatening world civilization, problems ranging from those of currency and the distribution of a food supply, now running to waste, to that which must be the pre-occupation of us all, the preservation of peace.

Finally, a word as to the biological study of man, to which Prof. Hooton would direct some of the creative energy now devoted to the interests of mechanization. It is difficult to avoid the conclusion that in the application of scientific investigation to the problems of man's future and the planning of human relations-which must come, if the world is not to drift into a worse chaos than that of the present time-the study of human heredity in all its aspects will play an important part. How far the study of eugenics, as at present pur. sued, will enter into the attack on this problem is an open question. Who is to decide what is the 
type to which to breed? Further, the proliferation of the alleged inferior classes of the population is, after all, only in accordance with Nature's method of ensuring in any species that out of an innumerable progeny the fit shall survive. This is not an argument in favour of the physically and mentally degenerate; but the history of
English society is the last which should be called on to testify that the product of any one grade is 'inferior'. If, however, it is maintained that such an excess in numbers of offspring constitutes a social burden, the argument is removed from the biological to a sociological plane and constitutes a problem of a different character.

\section{Dialectical Materialism in Biology}

\section{Biology and Marxism}

By Prof. Marcel Prenant. Translated by C. Desmond Greaves. Pp. xxiii +223 . (London : Lawrence and Wishart, Ltd., 1938.) 10s. 6d. net.

MANY readers of NATURE will ask what II Marxism has to do with biology. It would be possible to write a volume on the economic influences which have done much to determine the course of biological research. For example, botany was at one time largely concerned with medicinal herbs. The greatest age of systematic botany was that of the crude exploitation of Colonial floras, and interest in plant genetics arose with the need for improvement in Colonial plants, such as Canadian wheat and Javan sugar-beet.

But Prof. Prenant's book is an attempt to apply to biology the principles of dialectical materialism, the philosophy of Marx, Engels and Lenin. It was written for working-class students to whom Marxism is already familiar, and not primarily for biologists. Nevertheless, every biologist who recognizes that Marxism, whether true or false, is an important philosophical movement, will find the book extremely interesting.

The author points out that Marxist ideas are peculiarly applicable in biology because both biology and Marxism are concerned with change; and he is primarily concerned with evolution, both individual and social. Here Marx's and Engels' criticism of Darwin, whose results, as a whole, they accepted, is of great interest. In 1878, Engels wrote, "Darwin, when considering natural selection, leaves out of account the causes which have produced the variations in separate individuals, and deals primarily with the way in which such individual variations gradually become the characteristics of a race, variety, or species". On the other hand, many biologists will consider the criticism of Darwinism quoted on p. 194 less valid.

It is particularly interesting to see how a modern Marxist tackles some of the outstanding problems of biology. A Marxist must be materialistic without falling into mechanism, and Prof. Prenant certainly does his best to steer a course between the Scylla of epigenesis and the Charybdis of preformationism when discussing theories of embryonic development. In his account of heredity, while admitting the main results of the Morgan school, he stresses the importance of the cytoplasm, and above all the fact that at no time can the chromosomes be regarded as independent of their surroundings.

In my opinion, Prof. Prenant under-estimates the importance of selection for man. It is true that natural selection, in the strictly Darwinian sense of selective killing, has been largely replaced by what Karl Pearson called reproductive selection, based on differential fertility. However, under this new form, selection is perhaps as important as ever ; and Dr. Needham's critical notes show that there is plenty of room for divergence between Marxist biologists on quite fundamental questions.

Indeed, should interest in Marxism spread, as appears to be probable, there is no doubt that biological and other scientific problems will be more and more discussed from a Marxist angle. That this need not involve any slavish acceptance of Marxist writings as 'gospel' will be clear to any reader of Prof. Prenant's statement (p. 198) that "in explaining life as an innate property of protein Engels was straying from the dialectical path" Provided Marxists are willing to follow this example, I do not think that non-Marxist biologists need fear an attempt to impose Marxist dogmas on science, such as probably occurred in some quarters in the Soviet Union between 1922 and 1932 ; and they may even admit that Marxism makes for a novel approach to certain problems which is bound to stimulate thought and experiment.

The translation is almost uniformly excellent, and the publishers may be congratulated on a book which will certainly interest Marxists in biology, and should also interest many biologists in Marxism.
J. B. S. HALDANE. 